\title{
El declive del pueblo corporativo Atenquique
}

\author{
José G. Vargas Hernández
}

\section{Resumen}

Este trabajo se enfoca al análisis de los efectos que la transferencia de propiedad de una compañía papelera paraestatal a una propiedad corporativa que ha tenido en la declinación ambiental y económica en Atenquique. Esta transferencia fue el resultado de los procesos de globalización económica que se están llevando a cabo, después de un boom industrial de la compañía papelera durante la segunda mitad del último siglo. El trabajo también se enfoca en cómo los empleados de esta compañía productora de papel viven, y cómo han sido afectados por la globalización y cómo se sienten acerca de los nuevos dueños corporativos de la industria papelera. La metodología fue descriptiva y exploratoria. Se tomó una muestra de cuarenta trabajadores de la compañía que vivieron en Atenquique para una entrevista. Después de ser habitado el pueblo de Atenquique, se desarrolló en términos de población, sociedad y economía. De otra forma la Compañía Industrial de Atenquique creció durante el período cuando fue una propiedad del Estado mexicano. Después de la privatización de la compañía, el pueblo empezó de declinar y a encogerse en las tres variables arriba mencionadas. El impacto en el desarrollo ambiental y econó0mico ha iniciado el encogimiento y la declinación de Atenquique y las ciudades y pueblos que le rodean.

Palabra clave: Atenquique, desarrollo ambiental, desarrollo económico, declinación, modelo neoliberal, globalización.

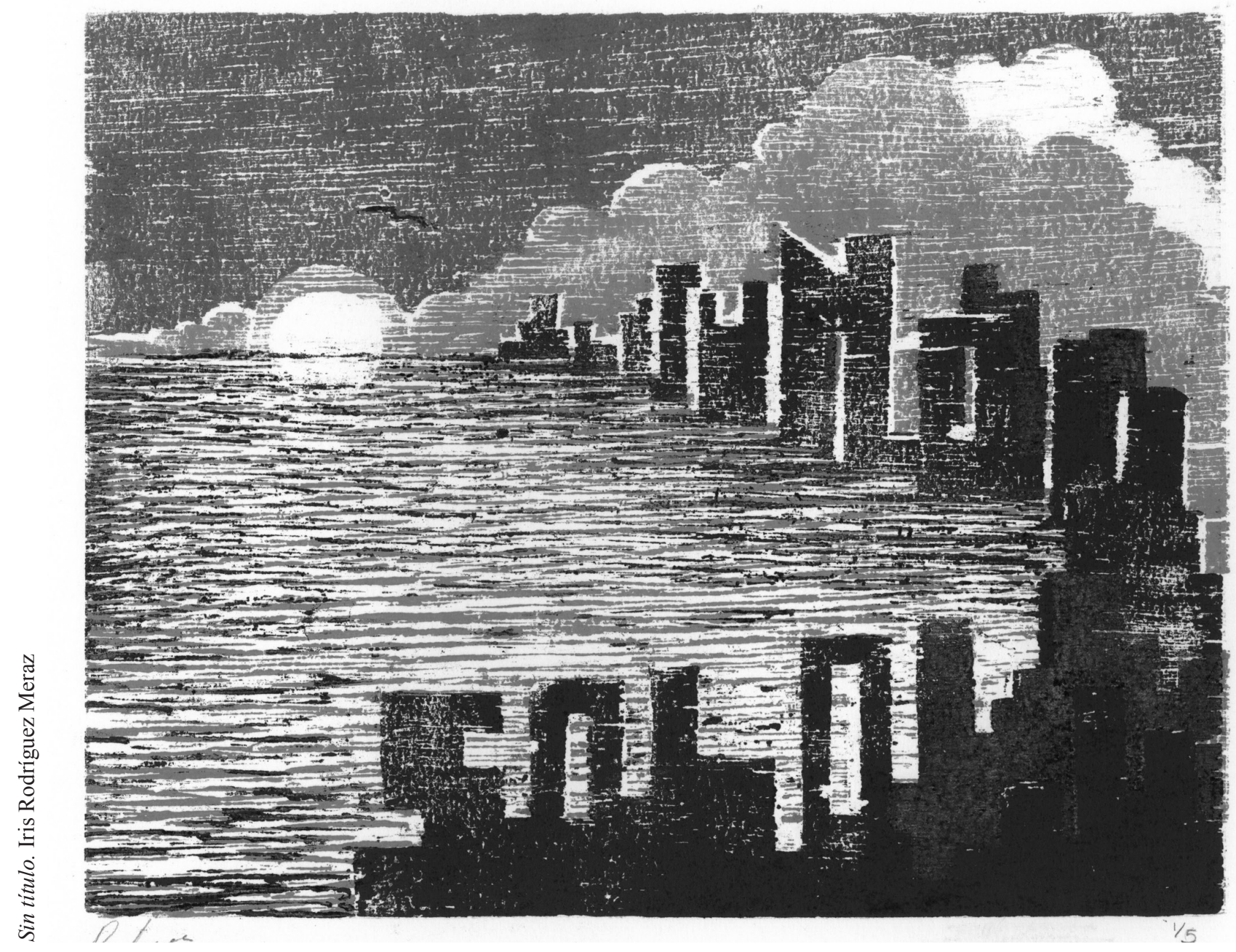




\section{輈 Sorvilo}

\begin{abstract}
This paper focuses on the analysis of effects that the transfer of ownership from a state-owned Paper Mill Company to a corporate private ownership has had environmental and economic shrinkage in Atenquique. This transfer was the result of the ongoing economic process of globalization, after the industrial boom of the paper mills during the second half of the last century. The paper also focuses on how the employees of this Paper Mill Company live and how they have corporate owners. The methodology used was descriptive and exploratory. A simple of forty workers at the company who lived in Atenquique was chosen for an interview. After being inhabited the town of Atenquique developed in terms of population, society and economy. On the other hand the Industrial Company of Atenquique grew during the period when it was a property of the Mexican State. After the company's privatization, the town started to decline and shrink in three abovementioned variables. The impact on the environmental and economic development has initiated the shrinking and declining of Atenquique and the surrounding cities and towns.
\end{abstract}

Key words: Atenquique, environmental development, economic development, shrinkage, neoliberal model, globalization.

\section{Introducción}

Durante los años de la década de los noventa del siglo pasado en México, se inicia un período de restructuración en las compañías papeleras, un proceso que ha sido caracterizado por grandes compañías de propiedad corporativa consolidándose para ser más grandes, más verticalmente integradas, transnacionales, menos diversificadas y ligeras. Estos cambios y desarrollos fueron iniciados debido a las tendencias a largo plazo hacia los procesos de globalización económica. En tanto que los procesos de globalización económica continúan, sus efectos en las comunidades locales son inciertos para las percepciones de sus residentes (Brady and Wallace 2000:91). La competencia global y la movilidad del capital han cambiado el inventivo de los nuevos dueños corporativos por las preocupaciones en los asuntos de las comunidades (Miller, 2006).

Una compañía privada de productos forestales basada en México, en la década pasada compró la fábrica de papel en Atenquique, una pequeña comunidad en la región Sur del estado de Jalisco. Cuando la compañía papelera fue fundada era propiedad del Estado y había financieramente apoyado la habitación, escuelas y otras actividades de la comunidad para los empleados y los trabajadores. Una corporación privada, Grupo Durango, compró la compañía papelera Atenquique propiedad del Estado y después de transferir la propiedad, los empleados han desconfiado y temido de los nuevos dueños corporativos. Esta desconfianza de los empleados apoya la mayor parte de la literatura que reporta los efectos de los procesos de globalización económica enfocándose en la privatización de las compañías que son propiedades del Estado.

Se ha dicho que en Atenquique los habitantes se acostumbraron a vivir como una gran familia. Las reuniones familiares se caracterizaron por un ambiente cálido de amistad, el espíritu de solidaridad en el trabajo y la afinidad de aspiraciones. Esta unificación y fraternidad de Atenquique fue apoyada por la Compañía Industrial de Atenquique, una fábrica papelera, y proveyó a la pequeña población con la infraestructura adecuada, edificios e instalaciones para promover la vida junto con los trabajadores y sus familias. Es por esta razón que la Compañía tuvo restaurantes, teatrosalón de cine, casinos y salas de lectura. Para promover la participación de los deportes entre los residentes de Atenquique, la compañía ofreció albercas, campos de juego para futbol, basquetbol, gimnasios, etc. (Medina Enríquez, 1988).

Para desarrollar las relaciones sociales entre la población, la compañía apoyó la formación de clubes con membresía para los trabajadores, empleados y sus familias para participar en concursos y certámenes de oratoria, poesía, conferencias y funciones teatrales. Escritores famosos, poetas e intelectuales atendieron los festivales culturales, así como el desarrollo de conciertos de música. Los empleados y los trabajadores formaron el Mariachi Atenquique, quienes acostumbraban tocar cada domingo por la noche en el Centro del poblado y junto con las escuelas de danza recibían el apoyo de la Compañía Papelera. En suma, en Atenquique se llevaba a cabo una intensa vida social y cultural como parte de una mejor calidad de vida. Fueron los tiempos cuando el desarrollo económico y ambiental de Atenquique estaba a la alza.

La Compañía Industrial de Atenquique fue una de las ventanillas o aparadores donde la emergencia de las instituciones económicas estructuradas, bajo el dominante paradigma ideológico del Estado Revolucionario Mexicano, estaba preocupado por 
el bienestar de los empleados, trabajadores y todos los grupos de interés. De hecho, la compañía fue una empresa pública y propiedad del estado y estaba relacionada con la creación de fuentes de empleo y bienestar para las generaciones posrevolucionarias de mexicanos que vivían en la Región Sur del estado de Jalisco. Sin embargo, los procesos de globalización económica han resultado en la privatización de la Compañía Industrial de Atenquique causando la declinación del desarrollo económico y ambiental de Atenquique y sus alrededores en la región Sur de Jalisco.

En las siguientes páginas, se describen los materiales y los métodos usados en el diseño de la investigación para continuar con la contextualización del establecimiento; para servir como marco de referencia de la localización geográfica, una breve historia del pueblo corporativo Atenquique y una historia corta de la firma. Después de todo, los resultados de la investigación se presentan seguidos de una discusión del análisis económico y ambiental de la situación. Finalmente, se hacen algunas recomendaciones y se siguieren algunas implicaciones de políticas.

\section{Materiales y métodos}

La metodología usada fue descriptiva y explicativa. Una muestra de 40 trabajadores de la compañía que vivieron en Atenquique fueron elegidos para una entrevista. Esta muestra representó el 3\% del total de la fuerza laboral en el tiempo en que la firma fue una empresa propiedad del Estado mexicano y el 9\% de la fuerza laboral actual, después de haber sido privatizada. Las entrevistas fueron conducidas en dos diferentes periodos de tiempo: 10 de ellas se condujeron en Diciembre del 2008 y 30 entrevistas se efectuaron en Agosto del 2009. Los criterios de selección para elegir a los trabajadores para ser entrevistados tuvieron que llenar los requerimientos de que ellos habían trabajado en la compañía y vivido en el pueblo de Atenquique durante el período de tiempo en que la firma fue propiedad del Estado.

Sin embargo, a pesar de que se prefirió que los mismos 40 trabajadores entrevistados todavía vivieran después de la privatización de la firma en el pueblo de Atenquique, fue imposible satisfacer este requerimiento porque la mayoría de ellos tuvieron que devolver sus casas a la compañía y abandonaron el pueblo. Las entrevistas se condujeron en privado donde los trabajadores fueron abordados fuera de los terrenos e instalaciones de la compañía. Se entregó a cada trabajador un guión escrito de la entrevista para su llenado, a pesar de que algunos de ellos prefirieron contestar oralmente y las respuestas fueron grabadas y se tomaron notas escritas de la entrevista. Las respuestas fueron grabadas y se tomaron notas escritas de la entrevista. Las respuestas fueron analizadas tomando en consideración la similitud de respuestas alineadas a los diferentes temas. El guión de la entrevista tenía cinco grandes preguntas: 1) ¿Desde cuándo ha vivido en Atenquique?, 2) ¿Desde cuándo usted ha trabajado en Atenquique?, 3) ¿Cuáles son los cambios más importantes que usted ha experimentado en Atenquique?, 4) ¿Cuáles son los cambios más importantes laborales que ha tenido en su trabajo? Y 5) ¿Cómo le han afectado estos cambios laborales?

\section{Localización del pueblo de Atenquique}

La población de Atenquique (19032’N 1030 30’W), está localizada al sur del estado de Jalisco (ver figura1, abajo), en la parte oriente al pie de los volcanes de Colima, a 1030 metros arriba del nivel del mar. El precipicio o barranca de Atenquique es 24 kilómetros de largo localizado en el banco Este del volcán Nevado de Colima y junto con otras barrancas, Los Plátanos y Arroyo Seco, forman la cuenca de Atenquique. La cuenca de Atenquique tiene la apariencia de un largo túnel con orientación Oeste-Este uniéndose al río Tuxpan. Atenquique está localizado a 11.3 kilómetros de Tuxpan, la cabecera municipal del mismo nombre, en la carretera libre 54 de México, como se puede apreciar en la figura 1, mapa de Atenquique y pueblos circunvecinos.

El Volcán de Colima es un volcán decadente y el más activo de México. Actualmente se está acercando a su fase climática y puede ocurrir una erupción mayor en la siguiente década. Los flujos de los derrames volcánicos es probable que ocurran en los dos drenajes mayores al Este y Oeste del volcán, el Río Tuxpan y el Río Armería respectivamente. Como el más grande productor de madera, Atenquique está en alto riesgo por moderar sus grandes deslaves de residuos volcánicos mojados por está cerca del volcán y al fondo de un cañón profundo (Saucedo Girón, Hernández Hernández y Macías Vázquez, S.f.). 


\section{就 Sorvio}

Figura 1. Mapa de Atenquique y áreas vecinales

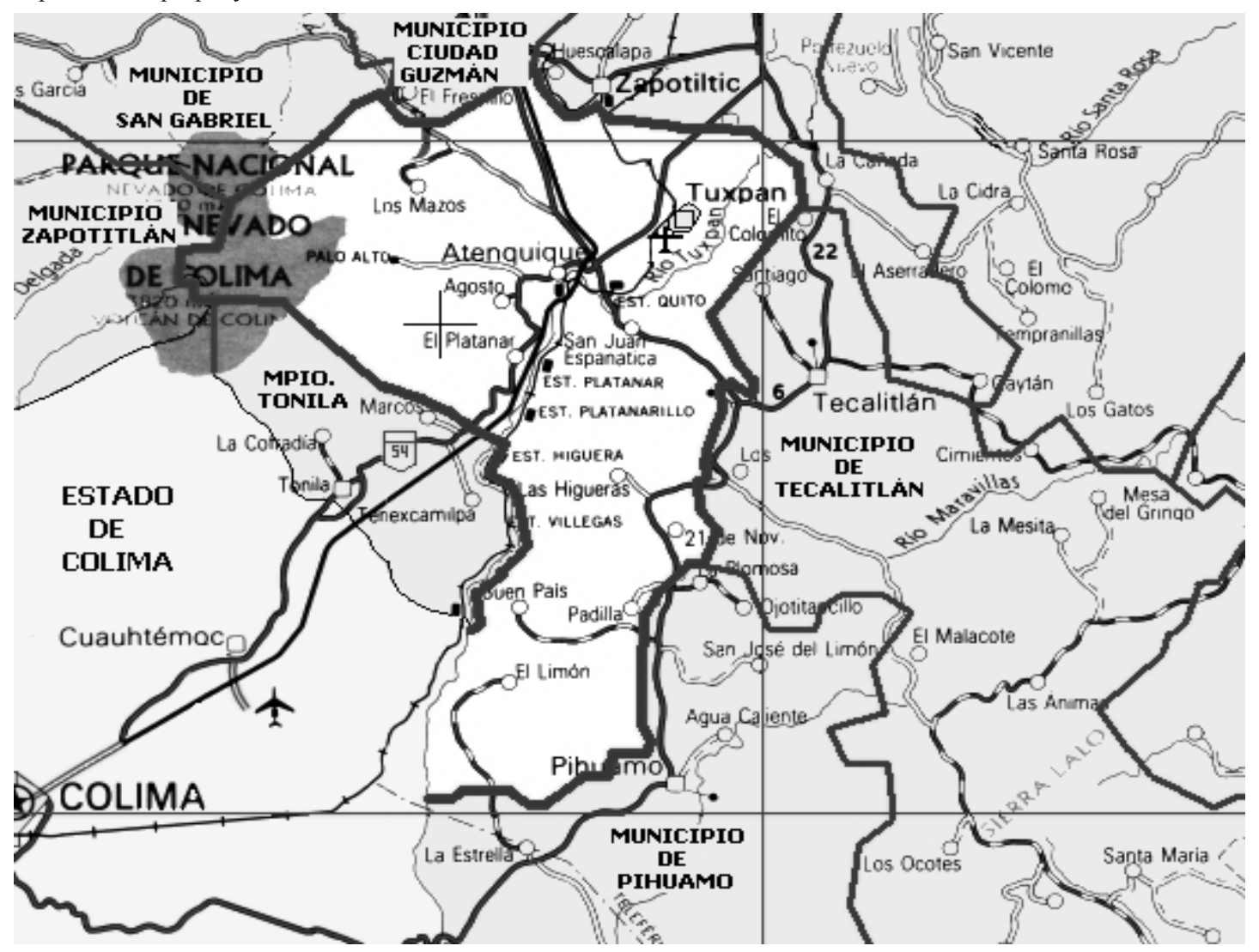

\section{Breve historia del pueblo corporativo de Atenquique}

Atenquique fue sitio de batalla en 1958. Antes de la construcción de la industria productora de papel, la villa solamente tenía 50 habitantes y fue conocida como un lugar de campamento. La Villa de Atenquique fue fundada en 1946 como la consecuencia del desarrollo de una empresa fabricante de papel denominada Compañía Industrial de Atenquique, S.A. (CIDASA), como un punto estratégico para capturar el agua de los dos ríos. El de Atenquique y el de Tuxpan, los cuales son vitales para la industria.

La Compañía Industrial de Atenquique fue inaugurada en Octubre de 1946 y llegó a ser la más larga en la Región Sur de Jalisco. Inmediatamente después de establecimiento de la Compañía, Atenquique tuvo una población de más de 4 mil habitantes, considerando la inmigración de los trabajadores y sus familias provenientes de las regiones y estados vecinos. Desde entonces, la fuerza de trabajo ha viajado desde los pueblos y ciudades vecinas y se sustenta en la compañía como su principal empleador.
Los habitantes avecindados en Atenquique recuerdan las contingencias por las que han pasado como una comunidad. El 16 de Octubre de 1955 inició una tormenta fuerte que duró tres días y causó una serie de flujos de lodazales y desechos de malezas los cuales devastaron casi toda la Villa de Atenquique. La tormenta causó una fuerte corriente con inundaciones provenientes del río Atenquique y derrumbes de las laderas de la barranca, que dieron por resultado la muerte de diez personas y destruyeron la iglesia, una escuela, varios negocios y tiendas, edificaciones y alrededor de 20 casas.

La tormenta también afectó la planta industrial y mató a 23 personas. Las inundaciones dejaron desolación y afectaron las operaciones de la compañía papelera por dos meses, la vía del tren y otros caminos se truncaron y los daños materiales fueron estimados en diez mil millones de pesos de ese tiempo. El asunto fue la ladera de la barranca de alta inclinación que se colapsó acerca de la villa. Este evento catastrófico forzó la creación de nuevos planes para Atenquique (Redacción Del Sur, 2005). Los residentes de Atenquique ayudaron a reparar 
los daños causados por las inundaciones y derrumbes a la Compañía de Atenquique.

A pesar de estas contingencias, después de la instalación de la compañía productora de papel en Atenquique, la población se duplicó en solo 20 años de 1950 a 1970, consolidándose a sí misma como un polo de desarrollo con atracción regional. En los noventas había más de 291 hogares con una población de 1,645 como se muestra en la tabla 1, la cual lista las más grandes localidades de las 82 existentes en el municipio de Tuxpan, como se reportaron en los censos de población. Hay que considerar además de Atenquique tuvo una importante población flotante que no fue registrada en dichos censos.

Tabla 1. Población en las principales localidades de la municipalidad de Tuxpan, Jalisco para los años 1990 y 1995.

\begin{tabular}{|l|ll|}
\hline $\begin{array}{l}\text { Nombre de } \\
\text { las localidades }\end{array}$ & \multicolumn{2}{|l|}{ Población (Año/habitantes) } \\
$\mathbf{1 9 9 0}$ & $\mathbf{1 9 9 5}$ \\
\hline Cabecera Municipal & 25,895 & 26,219 \\
\hline Atenquique & 1,645 & 1,237 \\
\hline La Higuera & 1,479 & 1,410 \\
\hline $\begin{array}{l}\text { San Juan Espanatica } \\
\text { (El Pueblito) }\end{array}$ & 908 & 792 \\
\hline $\begin{array}{l}\text { Pozo Santo } \\
\text { Platanar }\end{array}$ & 868 \\
\hline
\end{tabular}

Fuente: INEGI (2000).

Para el caso de Atenquique, se pudo determinar que había 1,645 habitantes en 1990 mientras que solamente había 1,237 in 1995, marcando una tendencia a la declinación en la población. Si se comparan los datos del número de habitantes que había en 1988 y la población que había en 2007, último para el que se tienen datos oficiales de población de Atenquique, los resultados son:

Tabla 2. Población de Atenquique

\begin{tabular}{|l|l|l|}
\hline Ã̃o & Población atendiendo educación & Población total \\
\hline 1988 & 750 & 3700 \\
\hline 2007 & 139 & 310 \\
\hline & -611 & -3390 \\
\hline
\end{tabular}

Fuente: Estimaciones propias después de contar y tomar un censo.

\section{Historia de la Compañía}

A pesar de que el área del Nevado de Colima fue declarada "zona protegida" en 1934 y considerada como parque nacional en los tiempos del presidente Lázaro Cárdenas, el decreto fue modificado dos años más tarde en 1936 para dar oportunidad a la compañía de Atenquique para explotar el bosque. La Reforma Agraria de la tierra implementada en México durante los años 30 y 40, dio parcelas de tierra comunal que dan lugar a los ejidos, a los campesinos pobres denominados ejidatarios, de tierras que fueron expropiadas de dueños privados que poseían grandes extensiones de tierras y bienes raíces, generalmente llamadas haciendas. A fin de explotar su tierra, los ejidatarios limpiaron los bosques y nivelaron los terrenos mediante la tala irracional de grandes superficies de bosques.

Los grandes dueños de tierras del Sur de Jalisco que controlaban los bosques, no solamente de los Volcanes de Colima, sino también de las montañas de Sierra del Tigre, El Halo y La Leona, organizaron la empresa Unión Forestal de Jalisco y Colima en 1940 para mantener de los recursos forestales y proteger los bosques de posibles riesgos.

El 26 de Noviembre de 1940, fue modificado el decreto nuevamente y el 7 de Septiembre de 1941, se fundó la Compañía Industrial de Atenquique, S.A. (CIDASA), para tomar ventaja de los recursos forestales en el Sur de Jalisco. El decreto estableció la concesión para la explotación forestal en el Sur de Jalisco por 50 años a favor de CIDASA para la elaboración de celulosas químicas, pastas mecánicas, papel, fibras sintéticas y diversos materiales plásticos.

La compañía manufacturera de papel CIDASA (Compañía Industrial de Atenquique, Sociedad Anónima) en Atenquique, fue creada por inversionistas locales y promovida por un militar Alemán. El gobierno federal mexicano otorgó un millón y ochenta mil hectáreas en concesión libre para la explotación durante los siguientes 50 años. Esta extensión representa el 1.7\% del total de los bosques en todo el territorio mexicano.

La Compañía Industrial de Atenquique (CIDASA), fue una empresa papelera propiedad del Estado. Desde el inicio, la Compañía se ha beneficiado por los incentivos fiscales. La compañía diversificó sus actividades productivas en un conglomerado integrado por la explotación de la madera, la extracción de celulosa y la manufactura de empaque.

El 22 de marzo de 1945, fue creada una unidad de explotación forestal industrial a favor de CIDASA con una concesión para explotar la Madera en una superficie de 225,000 hectáreas. Esta área fue distribuida en 17 municipalidades en la región sur de Jalisco, con una producción anual que variaba entre el 60 y 70 por 


\section{就 Sorvia}

ciento de la producción global del estado. El 27 de marzo de 1945, la Unidad Industrial de Explotación Forestal (UIEF) fue creada por decreto para consolidar el control de los bosques adoptando un régimen legal. En 1945, la Dirección Técnica Forestal fue creada con los empleados pagados por CIDASA. Por lo tanto, la organización en cargo de la supervisión Técnica de la explotación estaba en la nómina de la compañía que explotaba los bosques. Entre 1946 y 1948, se efectuó el Primer Inventario Forestal denominado Proyecto General de Ordenamiento.

Figura 2. Vista parcial de Atenquique. (Fuente: José Vargas).

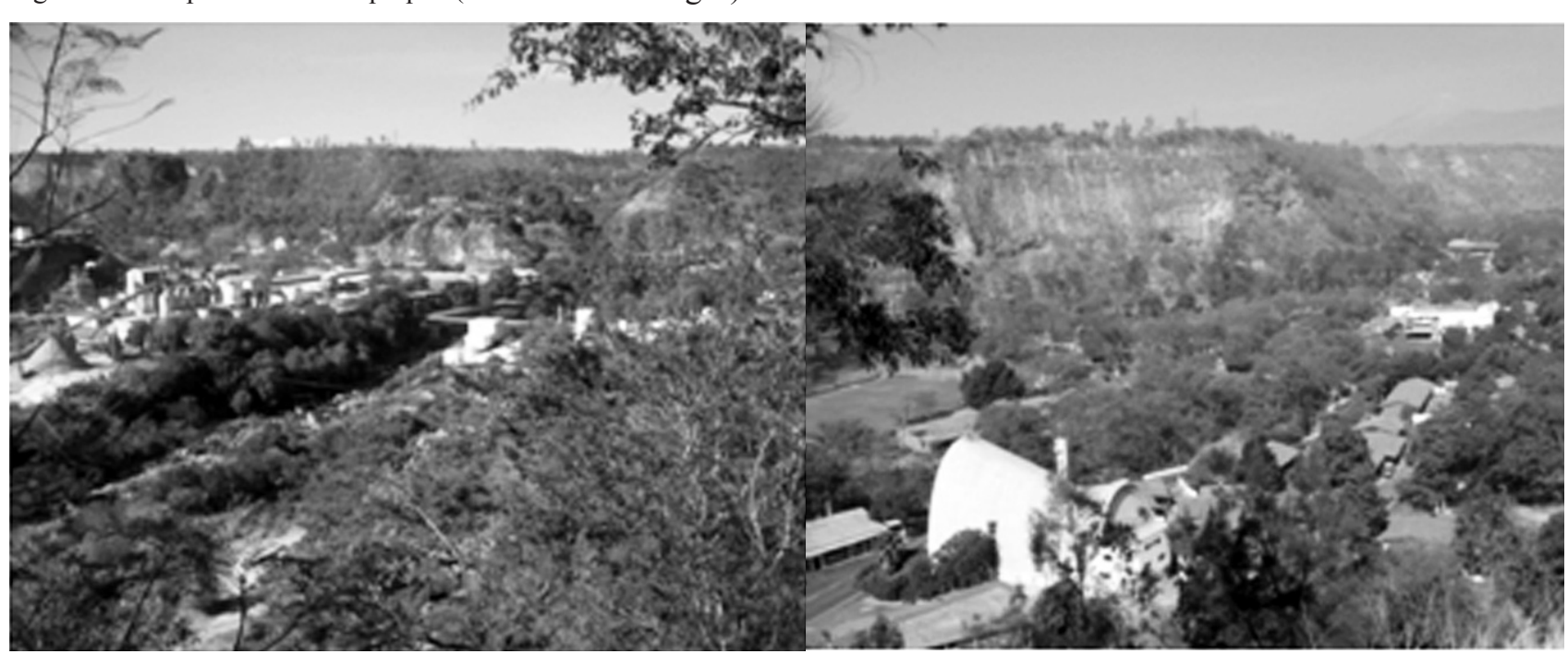

y otros productos. Una planta manufacturera de triplay se instaló a pesar de que los oyamelas, una variedad de árbol, eran escasos después de una explotación severa.

Las relaciones entre los residentes de las municipalidades vecinas, más específicamente entre las ciudades de Tuxpan y de Ciudad Guzmán fueron consideradas como una comunión de familiares, porque la compañía fue al decir de todos, "La herencia de nuestros padres". Los salarios generales oscilaban entre 150 y 160 pesos por día, a pesar de que algunos trabajadores ganaron más de 300 pesos por día (30 US dólares); justificada por la alta productividad y las
Hubo una crisis mundial del papel en 1954 que benefició la expansión de CIDASA; como resultado de la explotación forestal fue consolidada como la principal actividad económica dado su potencial y magnitud. En 1963 y 64, la planta de CIDASA fue modernizada y ampliada. Entre 1964 y 1968, dio inicio el Segundo Inventario Forestal. Una consecuencia inmediata de estos acuerdos fue que se aceleró la explotación de los recursos forestales. Para 1969, la modernización de la planta ya estaba consolidada incorporando nuevas técnicas y procesos.

En 1972, CIDASA llegó a ser una empresa propiedad del Estado debido a sus problemas financieros. En 1972, otro decreto amplió los usos de la explotación de madera por la Unidad Industrial de Explotación de madera por la Unidad Industrial de Explotación Forestal de Atenquique (UIEFA) de celulosa, papel cartón y papel madera, triplay, cartón de madera y otros productos. Una planta manufacturera de triplay, cartón de madera calificaciones personales. Considerados estos salarios a valor presente, los sueldos y salarios que pagaba CIDASA eran altos en comparación a trabajos similares en otras empresas.

La Compañía fue un imperio económico en la región sur de Jalisco porque usó los recursos concedidos por decreto que pertenecían a los ejidatarios dueños de un derecho para explotar una parcela de terreno y de los pequeños propietarios. Después de la crisis económica y financiera de 1982, la política económica trató el problema mediante el desmantelamiento gradual del Estado, vendiendo y privatizando las empresas públicas, fusionando, transfiriendo, cancelando y negociando las compañías mayores y dejando fuera del sector propiedad del Estado, las compañías menores. Después del final de la exclusiva concesión a la Compañía Industrial de Atenquique en 1990, la compañía fue vendida al 'Grupo Industrial Durango', S.A. de C.V. (GIDUSA) que pertenece a la familia Rincón Arredondo. 
GIDUSA fue fundada en 1980 y ha sido solamente el productor que ha integrado verticalmente la totalidad de proceso productivo de papel cartón y empaque de la explotación de la madera, celulosa, papel manufacturado y productos. La firma proveyó el 65 por ciento del cartón de empaque utilizado por el sector exportador mexicano, 80 por ciento del empaque mexicano utilizado por el sector de la maquila y el 40 por ciento del empaque consumido en el país. GIDUSA es la mayor compañía de madera y el mayor manufacturero de papel de estraza (papel café) y cartón de empaque en Latino América. También es dueño de 26 plantas manufactureras en México y 5 más en Estados Unidos. Actualmente, la Compañía Industrial de Atenquique es una de las subsidiarias del Grupo Industrial Durango.

Grupo Durango también posee Productora e Importadora de Papel (PIPSA), que controla 90 por ciento del papel usado en los periódicos en el mercado nacional. En 1998, el Banco Mexicano de Comercio Exterior (Bancomext) otorgó 80 millones de dólares a GIDUSA a fin de pagar sus deudas a los bancos después de comprar PIPSA. El gobierno mexicano remitió sus deudas para la adquisición de PIPSA, a pesar de que fue vendida a la mitad de su valor real (Proceso, 1999).

La desconfianza de la Compañía por la fuerza de trabajo se inició en la tercera semana de Abril del 2001, cuando 97 trabajadores de un total de 650 fueron despedidos porque se rescindieron sus contratos sin razón alguna; más tarde, 30 trabajadores perdieron sus trabajos. El 21 de abril del 2001, después de que la Compañía paró la producción para dar mantenimiento a la planta, declaró que no era competitiva. Desde ese momento, los trabajadores se declararon en huelga fuera de las facilidades de la compañía esperando una solución al conflicto (Rivera, 2001).

La firma cerró sus operaciones el 26 de abril del 2001, despidiendo a empleados y trabajadores. La Compañía de papel Kraft declaró que cerraba debido a un incremento de los costos de producción, y más específicamente a los incrementos en los costos laborales. Después de medio siglo de operaciones, la Compañía Industrial de Atenquique cerró sus puertas debido a los altos costos de operación, por lo cual debido a los incrementos en los costos de mano de obra según se declaró, 900 empleados perdieron sus trabajos. Trascendió que la Compañía había tomado y sacado el equipo y maquinaria fuera de la planta lo cual a su vez motivó la intensificación de las protestas de los trabajadores. (Milenio, 2001).
En realidad hubo dos diferentes versiones de por qué la compañía cerró: Los trabajadores argumentaron que la ambición de los accionistas y administradores del Grupo Durango fue la principal causa. La estrategia del sindicato fue evitar el cierre definitivo de la planta. Por su parte, la Compañía argumentó que el contrato colectivo de trabajo tradicional, firmado 55 años antes con un agregado de cláusulas benevolentes que beneficiaron a los empleados y trabajadores como resultado de las negociaciones entre el sindicato de los trabajadores y los representantes del Estado Mexicano y de la Compañía, fue la causa de su cierre.

Además, se argumentó que los altos costos de trabajo fueron el resultado de la falta de flexibilidad al cambio de la cultura laboral. Los nuevos dueños de la Compañía privatizada argumentaron que Atenquique tuvo el más viejo y el menos competitivo contrato laboral incluyendo cláusulas, términos y beneficios difíciles para entender (Milenio, 2001) en una economía de alta competitividad y fronteras abiertas a las importaciones.

Por lo tanto, el origen del conflicto fue eliminar el contrato colectivo y contratar personal bajo un nuevo esquema de condiciones laborales diseñadas para bajar los altos costos. Sin embargo, la Compañía aceptó que el principal problema fue la edad de los trabajadores que eran más viejos y mayores de los 35 años de edad. La amenaza fue localizar la planta en un lugar donde la Compañía pudiera lograr mayor rentabilidad. El mensaje fue claro: Suspender los contratos laborales que amenazaban los principios de la eficiencia productiva. El cierre de Atenquique significó que los derechos laborales logrados en medio siglo serían nulificados por la administración y el despido de 650 trabajadores sindicalizados, 120 empleados de confianza y 130 trabajadores eventuales.

El contrato colectivo estableció un límite a la producción diaria de 240 toneladas de papel, sin embargo al tiempo anterior a la huelga, la producción fue de más de 350 toneladas de papel.

Durante la visita del gobernador del Estado de Jalisco a Tamazula de Gordiano, una ciudad vecina a Atenquique, Guillermo Legarreta González, y el Secretario General del Sindicato Nacional de la Industria Papelera, expuso la situación de los trabajadores en GIDUSA y el Gobernador ofreció apoyo para solucionar el conflicto (Comunicación Social, 2001). Durante el conflicto laboral, el presidente municipal de Tuxpan, Tranquilino Rúa Laureano, afirmó que los trabajadores 


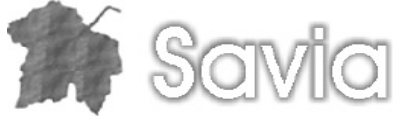

tuvieron su apoyo moral para encontrar una forma de solucionar el conflicto.

El 16 de mayo del 2001, el diputado local, Ramón León Morales, emitió un punto de acuerdo a la Comisión permanente del Congreso que fue turnado a la Comisión de Trabajo y Bienestar Social. El mandato de este punto de acuerdo fue encontrar una solución para mantener la fuente de trabajo, con respeto a los derechos contractuales laborales de trabajadores y empleados.

Sin embargo, después de varios mítines entre los administradores y los empleados para establecer una cantidad a ser pagada como liquidación a los trabajadores despedidos, no se alcanzó el acuerdo. Después de que la planta de papel GIDUSA había cerrado y todos los trabajadores y empleados despedidos, se anunció que la Secretaría de Promoción Económica del Gobierno del Estado de Jalisco sostendría programas de reactivación económica para crear empleo en el sur de Jalisco (Gobierno del Estado de Jalisco, 2004).

En las reuniones llevadas a cabo entre el Secretario del Trabajo, los líderes del Sindicato de trabajadores y los representantes del pueblo de Atenquique, la Compañía aceptó pagar el mantenimiento de los servicios primarios como los beneficios disfrutados por la población y que fueron proporcionados por la Compañía. También acordaron revisar el contrato colectivo para establecer los beneficios a los trabajadores a fin de reducir los costos de la producción del papel. La compañía también acordó firmar un nuevo contrato para volver a contratar a todos los empleados de la Compañía. La Compañía y los trabajadores aceptaron el compromiso, sin embargo, más tarde, la Compañía decidió no aceptarlo.

El Secretario del Trabajo tuvo que intervenir para alcanzar el acuerdo, después de que los trabajadores habían acordado recibir solamente una parte de los beneficios, para establecer el contrato colectivo de trabajo. El conflicto laboral en la planta de papel GIDUSA, fue parte de la estrategia de la Compañía para solucionar el contrato colectivo de trabajo para reducir los costos de trabajo. Todos los trabajadores y empleados fueron despedidos terminando el contrato colectivo de trabajo que había sido aplicado por 55 años, con un costo estimado de 160 millones de pesos. Una vez establecida esta relación laboral colectiva, Atenquique pudo abrir la planta sin la carga pesada del pago de beneficios laborales.

El 3 de septiembre de 2001, GIDUSA declaró que estaba lista para abrir de nuevo (El Financiero, 2001); invirtiendo 50 millones de dólares (Rodríguez, 2001). La nueva compañía fue denominada Compañía Papelera de Atenquique, S.A. de C.V., e inmediatamente inició operaciones con cerca del 50 por ciento de la fuerza de trabajo. Desde entonces la administración de la firma ha estado requiriendo nuevas actitudes hacia la asignación de trabajos multifuncionales, apoyadas por programas de entrenamiento y productividad. En términos generales, los salarios son más bajos que antes. Iniciando en febrero 2007, la firma cambió su nombre a ATENSA, S.A. de C.V., Empaques de Cartón Titán, S.A. DE C.V.

\section{Resultados y discusión}

El análisis de las entrevistas reveló que el 96\% de los individuos vivieron en Atenquique y trabajaron en la Compañía antes de la crisis. Los entrevistados de más edad comentaron que empezaron a trabajar en la Compañía o en otras compañías que formaban parte del grupo Atenquique tales como Unión Forestal de Jalisco y Colima, Aserraderos Técnicos, etcétera. Las entrevistas revelaron que los cambios importantes en Atenquique estaban relacionados con el ciclo de vida de la firma, tales como el cambio de propiedad en 1987, cuando fue privatizada y vendida al Grupo Durango.

Otro importante cambio enfatizado en las entrevistas fue el cierre de la Sección XI del Sindicato de Trabajadores de la Industria Papelera en el año 2001, cuando la mayoría de los trabajadores y empleados fueron despedidos por la Compañía. A fin de cancelar el Sindicato de Trabajadores, la Compañía cerró operaciones y se declaró en quiebra. Solamente una parte de los trabajadores sindicalizados fueron recontratados bajo contrato de trabajo individual. Sin embargo, después del fin de este contrato fueron transferidos a otra compañía del grupo Durango con los mismos términos y condiciones de un nuevo contrato de trabajo individual.

Los cambios importantes experimentados por los entrevistados incluyeron que cuando empezaron a trabajar para la Compañía requirieron de competencias para el buen desempeño y una mayor productividad. Otros cambios reportados fueron el ajuste y adaptación al trabajo, las promociones laborales en la Compañía, cambios en la información y en los sistemas de datos, reducción de personal y nuevas contrataciones.

De los cuarenta trabajadores entrevistados, 37 acordaron que el punto de retorno en su trabajo en la 
Compañía fue marcado en septiembre del 2001 cuando después de la crisis, la sección XI del Sindicato de la Industria Papelera fue eliminado y la nueva compañía denominada empezó sus operaciones y empezó a contratar trabajadores sin experiencia y sin beneficios laborales y requerimientos de trabajo. Las presiones fueron altas en mayor eficiencia, productividad, con menos recursos y nuevos retos. Los empleadores mantuvieron los mismos salarios, pero menores beneficios laborales que cuando la compañía era propiedad del Estado Mexicano.

Las entrevistas revelaron que hay más presiones; el ambiente laboral y el clima laboral son más tensos y más estresantes en contraste a los tiempos cuando la Compañía era propiedad del Estado Mexicano. Los empleados y trabajadores tenían un ambiente más relajado, menos presión en las tareas y más personal asignado para desempeñar las mismas responsabilidades. Bajo la nueva administración se incrementó el estrés cuando los empleados y los trabajadores fueron requeridos para mantener los recursos y algunos beneficios laborales fueron removidos, tales como llantas para automóviles, bonos de gasolina, compartir las utilidades, etcétera.

Cuatro de los entrevistados capturaron la situación declarando que durante el tiempo en que la Compañía era propiedad del Estado Mexicano la supervisión fue difícil porque el personal operativo con membresía sindical era flojo y negligente. Cuando la nueva compañía inició en septiembre del 2001, después de que la compañía anterior se declaró en crisis y en bancarrota, todo el personal afiliado a la Sección del Sindicato fue despedido, aunque algunos de ellos fueron recontratados, pero la mayoría del personal fueron contrataciones nuevas.

Los aspectos positivos de los cambios laborales identificados durante las entrevistas revelaron que las experiencias laborales del personal de la compañía, tales como una mayor participación de los trabajadores, ganar más dinero, más opciones laborales, más aprendizaje y sobretodo la oportunidad de tener un trabajo en estos tiempos tan difíciles en que escasea. 28 de los entrevistados declararon que los cambios laborales de la Compañía les han favorecido porque han recibido más entrenamiento. Siete de los que respondieron concluyeron que han estado más motivados por todos los eventos causados por los cambios de la globalización, los tratados comerciales y el desempleo, porque ha causado que la gente valore las fuentes de trabajos y las luchas por la compañía para sobrevivir en la región sur de Jalisco.
Cinco entrevistados reportaron que los cambios laborales les han beneficiado, porque han logrado promociones en posición de puesto con sus consiguientes salarios. Además, otros entrevistados declararon que a pesar de que los cambios laborales son más estresantes y con mayores presiones, ha percibido que dichos cambios han sido positivos. El argumento es debido a la devaluación del poder adquisitivo de los salarios, los trabajadores necesitan lograr objetivos para mantener sus salarios.

En términos generales, las personas empleadas en la Compañía percibieron que ya iniciaron a trabajar y hasta ahora, el personal ha mejorado sus actitudes y su productividad. El personal ha desarrollado más habilidades y se han convertido en multifuncionales. Por ejemplo, un mecánico ahora conoce de soldadura y de pintura, y realiza las dos funciones en la empresa. Antes, este mecánico trabajaba siempre con un compañero y ahora trabaja por si mismo.

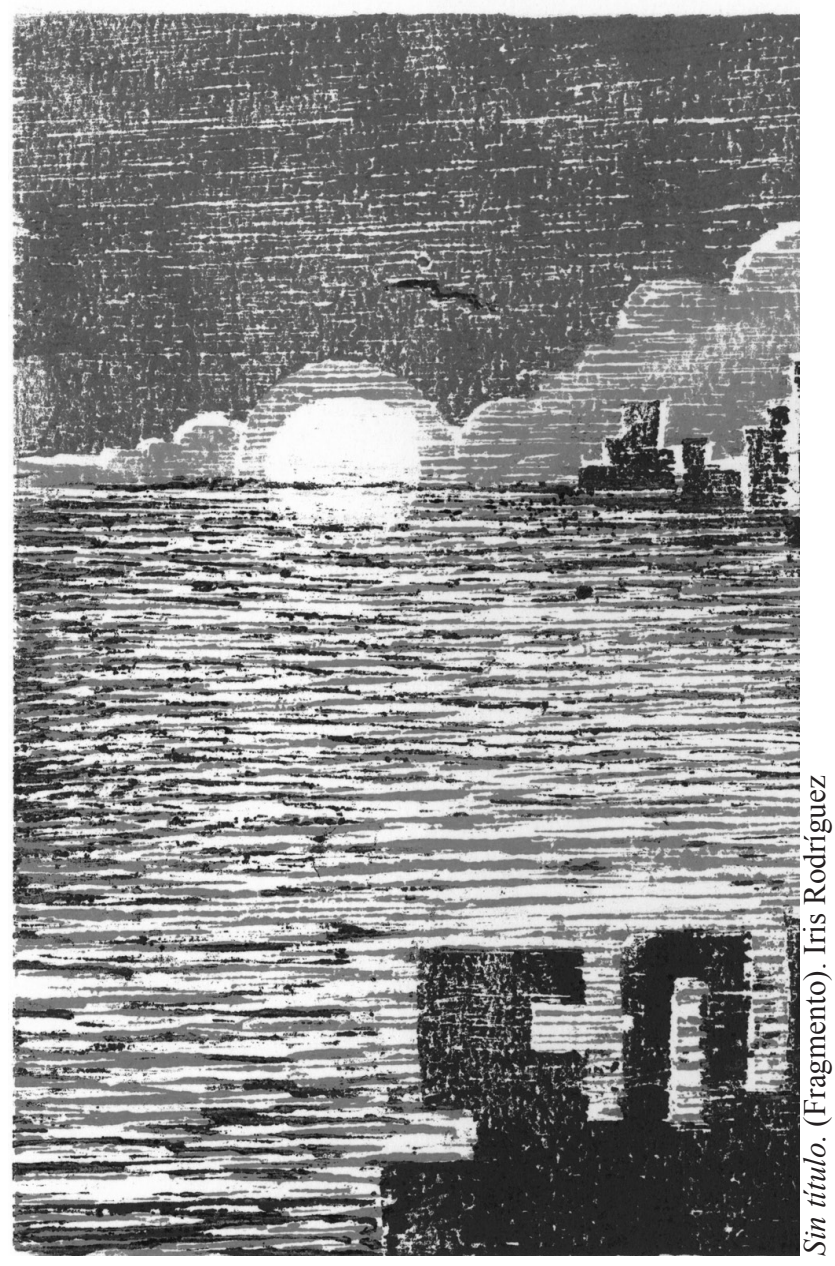


Entre los impactos negativos de los cambios laborales en la compañía reportados por 39 de cuarenta de los trabajadores entrevistados, es que trabajan bajo presión, se trabaja más tiempo que un día laboral ordinario de ocho horas y sin recibir pago por tiempo extra o negociación de horas trabajadas por intercambio por tiempo más flexible cuando se requiera para atender problemas personales, tales como atención a la salud. Otros efectos son los bajos salarios y pocos empleados y trabajadores para las mismas actividades. Tal como 5 entrevistados declararon, el efecto negativo de las presiones del trabajo y el estrés para lograr las metas de productividad, produjeron mejores resultados con menos costos para la compañía.

Otro aspecto negativo reportado durante las entrevistas fue que el ambiente laboral es pesado y estresante. Los administradores de la compañía están obligados a obtener utilidades pasando de lado las presiones y manipulando al personal para obtener un mejor desempeño. Un entrevistado sustentó que "había sido manejado psicológicamente para hacernos creer que nosotros somos los dueños del progreso y que somos responsables por buenos resultados". Es un objetivo de escalamiento hacia arriba, siempre mejorando la productividad.

\section{Desarrollo regional económico ambiental}

\section{a. Análisis del impacto}

Lo que una vez se consideró el motor económico de la Región Sur de Jalisco por más de 55 años, cerró sus puertas en el año 2001. El conflicto laboral tuvo impacto en lo económico y social no solamente en la región Sur de Jalisco, sino que en todo el Estado de Jalisco. No solamente tuvo un impacto económico sino que tuvo implicaciones afectivas. El 95\% de los trabajadores de Atenquique fueron originarios de Tuxpan, una municipalidad que tenía 33 mil habitantes. La principal actividad económica de Tuxpan es la agricultura con cultivos de caña de azúcar y vegetales.

Desde marzo de 1995 a diciembre del 2000, las inversiones en la región del Sur de Jalisco sumaron 55 millones de dólares, los cuales representaron el 98 por ciento del total en el Estado de Jalisco, de acuerdo a la Secretaría de Promoción Económica del Gobierno del Estado de Jalisco, 1995-2001 (Gobierno del Estado de Jalisco, 2004).

La Compañía de Atenquique, por su parte, proveyó empleo directo a más de 1,000 trabajadores, lo cual tuvo un impacto económico no solamente en Atenquique sino también en las ciudades y pueblos vecinos de Tuxpan y Ciudad Guzmán y los pueblos de Zapotilic, Tecalitlán, etc. Se ha calculado que la derrama económica era de alrededor de 150 pesos por trabajador en promedio, lo cual representa un total de 150 mil pesos por día o 22 millones ochocientos mil por mes.

En total 650 trabajadores más 300 empleados, fueron afectados por no ganar sus salarios durante la crisis con el impacto en los estándares de vida de 4,750 habitantes. Fue estimado que 4 de cada 10 familias en la municipalidad de Tuxpan dependieron del ingreso de los trabajadores de Atenquique. Más de 600 familias fueron directamente dañadas en su ingreso. El impacto inmediato en la economía local de Tuxpan fue de un $60 \%$ de caída en las ventas y como consecuencia también declinaron las ventasen el mercado regional de Ciudad Guzmán.

Un estudio de la Legislatura del Estado concluyó que el efecto de la multiplicación de la derrama de los salarios se estimó que era de alrededor de 800,000 pesos por mes y solamente en la municipalidad de Tuxpan. Sin embargo, el estudio debería haber considerado el impacto en Mazamitla, Tecalitlán, Tamazula de Gordiano, Tolimán, Zapotiltic, Zapotlán El Grande y otras localidades en el estado de Colima mediante las limitaciones al consumo y erosión de las condiciones de vida.

Los efectos económicos del conflicto laboral fueron visibles en el tianguis, el mercado tradicional de la calle del domingo, donde había pocos clientes. Los salarios ganados, como la sustentabilidad económica directa de las familias y también indirectamente, fueron dependientes del conflicto laboral. Por ejemplo, como una consecuencia del conflicto laboral, se estimó una reducción de alrededor del $40 \%$ en el ingreso de los restaurantes.

El promedio de antigüedad de los trabajadores y empleados quienes tuvieron una aspiración legítima para conseguir una pensión era de alrededor de 20 años de servicio. La mayoría de estos trabajadores no tienen otra oportunidad para ser empleados o para iniciar sus propios negocios debido al desarrollo económico negativo de la región en este año del 2001. Por esta condición la región fue fiscalmente favorecida.

El impacto social en el análisis de la Legislatura del Estado implicó que el cierre de la Compañía podría haber sido el origen de la desintegración familiar, 
problema de salud, nutrición, educación, migración y criminalidad. La Secretaría de Promoción Económica anunció que tenían un diagnóstico para encontrar soluciones y alternativas económicas a los problemas derivados del despido de los trabajadores de Atenquique.

El Presidente Municipal de Tuxpan sugirió que algunas medidas correctivas fueron tomadas a fin de atraer más inversiones a la municipalidad para evitar ser altamente dependientes económicamente de una sola Compañía. Empresarios coreanos involucrados en la industria metal-mecánica, planearon establecer una planta en la municipalidad de Tuxpan. Fue considerada como una alternativa para crear empleo, pero desafortunadamente las negociaciones estuvieron equivocadas y erróneas.

De hecho, el presidente Municipal Rúa Laureano había iniciado las negociaciones para atraer la inversión coreana que debería haber generado 3 mil puestos de trabajo a corto plazo y 10 mil a largo plazo, a pesar de que sólo las mujeres serían empleadas. Esta planta, de haberse instalado podría haber interrumpido la tendencia de la migración hacia el norte, principalmente a la zona fronteriza y a los Estados Unidos de las generaciones jóvenes, que dejan detrás sus sobrevivencia. Los hombres jóvenes tienen que migrar buscando el empleo y mejores condiciones de estándares de vida.

\section{b. Análisis del impacto ambiental}

Desde la segunda mitad del siglo pasado, la degradación ambiental en la región ha sido significativa y ha alcanzado dimensiones alarmantes cuando sobrepasó la capacidad natural de la regeneración natural de las comunidades forestales. El problema más serio de la región Sur de Jalisco ha sido la deforestación irracional que inició con las operaciones de CIDASA y luego GIDUSA. El Gobierno Federal también modificó los límites del área protegida que se redujo desde los 2,300 metros sobre el nivel del mar a 3,000. Sin embargo, estos límites nunca fueron bien definidos y se han confundido.

Por lo tanto, la Compañía tomó ventaja del Parque Nacional y devastó los recursos forestales, tuvo la capacidad de transformar alrededor de 200 mil metros cúbicos de madera por año, lo cual representó una cantidad enorme de árboles cortados.

Los abundantes recursos ecológicos sin casi ninguna restricción, motivaron que la compañía sobrexplotara más de 230 mil metros cúbicos de madera anualmente, muy por arriba de la capacidad sustentable de regeneración forestal del área. Por lo tanto, Atenquique elevó su productividad en más de un millón de metros cúbicos de madera, más de cinco veces la capacidad de regeneración de bosque. Esto causó una debacle ecológica de los bosques de la región del Sur de Jalisco.

Como resultado de 50 años de la explotación forestal, la vegetación secundaria y las áreas deforestadas fueron utilizadas para la agricultura y para la ganadería, la infraestructura y la explotación comercial. La compañía subutilizó los recursos forestales pero no tenía planes para los subproductos secundarios derivados de la madera. La Compañía explotó el pino para la manufactura del papel y los olmos para la industria del mueble, pero nunca explotó los cientos de toneladas de los sobrantes que eran desperdicios que se echaron a perder.

Además, ha habido intereses de otros agentes económicos, actores políticos y sociales, principalmente intermediarios, entre otros los denominados "coyotes", quienes son ambiciosos para tomar ventaja de los recursos forestales y de la madera de las comunidades locales. No hay otra forma de salirse y evitar las prácticas de oportunismo y corrupción de estos agentes y actores, sino de mantener una relación de cliente con los dueños de la industria de la madera que administran el manejo de los bosques.

Muchos dueños de los bosques, pequeños propietarios o ejidatarios, decidieron explotar sus propios recursos y proliferaron los aserraderos; muchos de ellos con operaciones clandestinas, que llegaron a ser alrededor de 25 tan sólo en Ciudad Guzmán, que operaban y explotaban los bosques irracionalmente, argumenta García de Alba, (2004). Esta explotación irracional es la causa de la inestabilidad del suelo y de las crecientes inundaciones de lodo y residuos de los árboles en tiempos de lluvia. Cuando la naturaleza forestal es removida, las raíces de los árboles no pueden retener y compactar el suelo de los terrenos, los cuales debido a los altos desniveles de las laderas de las colinas, el agua erosiona los terrenos y causa las remociones del flujo de los materiales orgánicos.

Varios sistemas de administración forestal se han implementado de acuerdo a las necesidades, tales como el Método Mexicano de Ordenación de Bosques Irregulares (MMOBI), el Método de Desarrollo Silvícola (MDS), plan Costa de Jalisco, Plan de Manejo Integral para la Región (SICODESI), Sistema 


\section{就 Sorvio}

de Manejo Integral (SIMANIN). Sin embargo, los resultados de implementar estos planes no son positivos, principalmente debido a que la corrupción es el factor principal.

Después del temblor de Armería del 21 de enero del 2003, la dinámica geomorfológica de la Cuenca de Atenquique se ha acelerado. Esta dinámica puede generar flujos de detritos en el corto plazo, como ha sucedido ya anteriormente en octubre de 1955, cuando destruyó una gran parte de Atenquique. Es necesario incorporar en los planes de desarrollo urbano los riesgos por los flujos de detritos en la localidad de Atenquique. Los fenómenos naturales tales como los derrumbes de las colinas y los deslaves, cuando los materiales repentinamente y rápidamente se separan creando flujos de lodo y otros residuos naturales siempre causan desastres naturales en las áreas geográficas aledañas al mismo poblado de Atenquique (Suárez Plascencia, Núñez Cornú y Díaz Torres (s.f.).

La otra área de alta concentración de deslaves está localizada en un área que forma una franja estrecha en

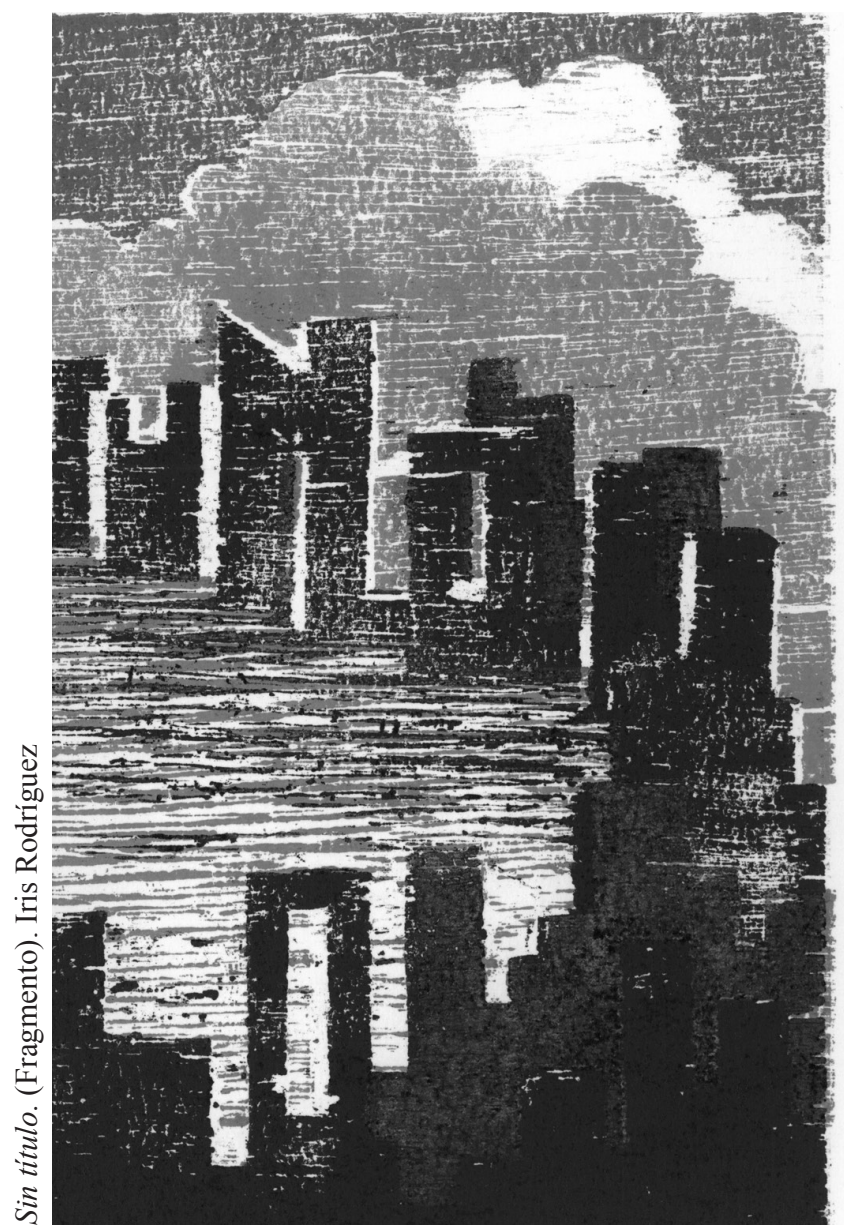

la Barranca de Atenquique, la cual es un cañón profundo y escalo0nado que corta el flanco oriental del nevado de Colima. En el flanco Sur del Volcán de Fuego y en línea con varios años pequeños al sur de la Barranca de Atenquique; las concentraciones de deslaves moderados evidentemente involucran materiales similares a aquellos que se dan a lo largo de la Barranca de Atenquique.

Otro impacto ambiental son los derrames y desechos de aguas residuales vertidos sobre el río Tuxpan que contamina las Corrientes de agua y ponen en riesgo y peligro la existencia de otras formas de vida, principalmente la animal. Se han presentado casos de intoxicación de ganado que abreva en las aguas del río más debajo de la Planta de Atenquique.

\section{Recomendaciones e implicaciones en las políticas}

A nivel macro, es necesario cambiar el marco de referencia legal existente en la Constitución Mexicana y las correspondientes leyes regulatorias federales y estatales relacionadas con los asuntos del uso y explotación de los recursos naturales y ambientales, y más específicamente con los recursos forestales y maderables como las leyes que conciernen a la conservación de los bosques. De tal forma que la explotación de la madera sea más racional y bajo principios de sustentabilidad de la comunidad. Son necesarias las nuevas legislaciones y la creación de nuevas instituciones que alienten el desarrollo y manejo sustentable de los bosques y selvas.

Los bosques han sido elevados a la categoría de asunto de seguridad nacional con el reconocimiento total de sus implicaciones en el desarrollo económico y bajo la tutela de Plan Nacional Forestal del Gobierno Federal Mexicano. Sin embargo, hay evidencias probadas por diferentes estudios contra las figuras oficiales de que el asunto de los bosques ha caído a la prioridad número 40 o más bajo de la agenda del Gobierno Federal, llevando hacia la total extinción de los bosques y selvas. Las causas del deterioro ecológico y forestal con sus implicaciones en el crecimiento económico y el desarrollo social están conectadas con la implementación de políticas públicas inapropiadas. Desesperadamente son necesarias políticas públicas inapropiadas. Desesperadamente son necesarias políticas públicas para mejorar el crecimiento económico y el desarrollo social de las comunidades que siempre han dependido de los recursos naturales en áreas de reserva de protección natural. 
El presupuesto del gobierno para atender las necesidades de la administración de los bosques y selvas necesita incrementarse de 0.01 por ciento del presupuesto total del Gobierno Federal, para apoyar programas que también son requeridos para ser aplicados ampliamente en las áreas forestales específicas de acuerdo a metas establecidas. Sin embargo, las finanzas para traer estos cambios se rezagan. PROFEPA, la Procuraduría Federal para la Protección Ambiental, es la Agencia Federal encargada de la protección de los recursos forestales que tiene las obligaciones y responsabilidades de vigilancia y auditoría ambiental, inspección industrial; administra las denuncias e implementa las revisiones de las disposiciones legales, enfrenta muchos retos en la procuración de la justicia ambiental y ha sido acusada de corrupción. La corrupción es endémica entre los oficiales, debido a los bajos salarios de los inspectores, por lo tanto, para cortar o bajar estas actividades de corrupción se requiere elevar los sueldos. Las actividades ilegales de la extracción de madera en las comunidades forestales causan el deterioro de los bosques y destruye la vida de las comunidades. Las nuevas medidas sobre la regulación de las actividades de explotación forestal han probado que son más dañinas a las prácticas comunitarias para la administración sustentable y uso de los recursos naturales.

La deforestación permanecerá como un gran problema en el Sur de Jalisco con serias consecuencias en la erosión de los suelos, lo cual a su vez amenaza la biodiversidad de la vida, la desaparición de habitantes naturales y el cambio de micro climas. Se requieren varias iniciativas para resolver los problemas de las actividades ilegales en la extracción de la madera, tales como el corte ilegal en las áreas protegidas de tierra para el cultivo forestal. Los bosques alrededor de las ciudades, pueblos y villas en la Región Sur de Jalisco han sido devastados por concesiones para la explotación del corte de la madera en pequeña escala.

Las acciones dirigidas a bajar la deforestación y a incrementar la reforestación deberían ser impulsadas e implementadas por los gobiernos locales; pero también por las comunidades y los dueños de los terrenos con bosques, pequeños propietarios o ejidatarios. La gobernabilidad forestal local, la administración de los programas forestales y los planes de incentivos para alentar el uso sustentable de los recursos naturales, se requiere para la práctica de las comunidades forestales. En lugares donde estas comunidades forestales se practican, los gobiernos locales y los dueños de los terrenos tienden a proteger los recursos naturales.

Las comunidades forestales en el Sur de Jalisco, tales como Atenquique que han dependido de la madera y la explotación forestal desde antes por el ingreso, necesitan desesperadamente diversificar las actividades económicas tales como el turismo ambiental y ecológico y el turismo rural para tomar ventaja de las rutas naturales que los rodean. Las actividades forestales pueden ser ligadas al ecoturismo y a otras actividades ambientales y productos que no sean de madera tales como los botánicos, las artesanías, etcétera. Además, el gobierno local debe promover programas de empleo alternativo con la administración sustentable de los recursos naturales.

Una perspectiva integral de las implicaciones de la administración de los recursos naturales tales como el desarrollo forestal, económico y social debe ser el fundamento para cualquier planeación estratégica del desarrollo regional en el Sur de Jalisco, que debe involucrar a todos los actores y agentes para generar las condiciones apropiadas para el bienestar de las comunidades.

\section{Bibliografía}

Brady, D., and Michael Wallace. (2000). Spatialization, foreign direct investment, and labor outcomes in the American states, 1978-1996. Social Forces. 79 (1):67-99.

Comunicación Social. (2001). Plantean al Gobernador el problema del cierre de La Papelera de Atenquique. Boletín del Gobierno del Estado de Jalisco. 101/2001 del 7 de Mayo.

El Financiero. (2001). Gidusa, lista para la reapertura de Atenquique. El Financiero. 3 de septiembre del 2001. p. 53.

García de Alba, R. (2004). Cuenca de Zapotlán. Deforestación y deterioro ambiental. IV Taller internacional de rehabilitación de la laguna de Zapotlán. Ciudad Guzmán. Centro Universitario del Sur. 13-15 Octubre.

Gobierno del Estado de Jalisco. (2004). Modelo de ordenamiento ecológico. Secretaría del Medio Ambiente para el Desarrollo Sustentable. Guadalajara, Jalisco. 


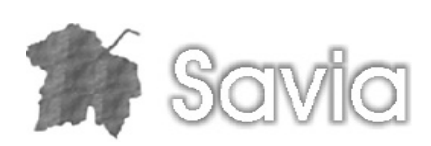

INEGI. (2000). Censo de Población. Instituto Nacional de Estadística, Geografía e Informática. Aguascalientes, Aguascalientes.

Medina Enríquez, J. (1988). Atenquique una aportación a su historia. ¿Historia para qué? México, D.F: Siglo XXI Editores. pp. 171-180.

Milenio Diario. (2001). Nocaut a Atenquique. Milenio Diario. Mayo 2.

Miller, C. D. (2006). Fear and Loathing in a Paper Mill Town: Local Perceptions of Globalization. The Journal of Regional Analysis and Policy (JRAP) 36(2): 171-181.

Paul, Y. and Sheridan, M. F. (s.f.). Estimated lahar hazard zones ay Volcán Colima, México. Departament of Geology. SUNY at Buffalo, Buffalo, N.Y. 14260.mfs@acsu.buffalo.edu.

Proceso. (1999). Atenquique en crisis. Revista Proceso. Noviembre 7.

Rivera, R. (2001). Nota. Gaceta Universitaria. 4 de Junio del 2001 (6).

Redacción del Sur. (2005). A 50 años de la tragedia de Atenquique. Periódico El Sur. Domingo 16 de Octubre.

Rodríguez, L. A. (2001). Invertirá Gidusa 50 mdd para reabrir la planta de Atenquique. El Occidental. 14 de septiembre del 2001. p. 28.

Saucedo Girón, R., Hernández Hernández, C. y Macías Vázquez, J. L. (s.f.) El lahar de Atenquique disparado por una lluvia extraordinaria el 16 de octubre de 1955 en el complejo volcánico de Colima, México. Mimeo. No publicado.

Suárez Plascencia, C. y otros. Caracterización geomorfológico de la Cuenca de Atenquique del complejo volcánico. Volcán Nevado de Colima, como insumo para la evaluación de riesgos por flujos de Detritus. Mimeo publicado. 